\title{
INVESTIGATING INDIVIDUAL FACTORS RELATED TO READMISSION OF PATIENTS WITH TYPE 2 DIABETES- A CROSS-SECTIONAL STUDY
}

\author{
Valiallah Dashtpour ${ }^{1}$, Mehran Hesaraki $^{2}$, Mahnaz Abavisani3 ${ }^{3}$ Mahdieh Sari ${ }^{4}$, Sudabeh Ahmadidarrehsima ${ }^{5}$ \\ 1M.Sc., of Medical Surgical Nursing, Department of Nursing, AJA University of Medical Sciences, Tehran, Iran. \\ 2M.D., Department of Paediatrics, Zabol University of Medical Sciences, Zabol, Iran. \\ 3M.Sc of Medical Surgical Nursing, Neyshabor University of Medical Scineces, Neyshabor, Iran. \\ ${ }^{4}$ M.Sc., Department of Nursing, Student Research Committee, Zabol University of Medical Sciences, Zabol, Iran. \\ ${ }^{5}$ Department of Nursing, Nursing and Midwifery School, Jiroft University of Medical Sciences, Jiroft, Iran.
}

\begin{abstract}
BACKGROUND
ABSTRACT

Diabetes mellitus, especially type 2 diabetes, is one of the main threats to human health in the contemporary century, and diabetic patients may frequently require hospitalization due to the chronic nature of their illness, that this issue causes various problems, such as increasing economic costs. The present study was conducted in order to determine the individual factors related to readmission of patients with type 2 diabetes in Bandar Abbas hospitals in 2017.
\end{abstract}

\section{MATERIALS AND METHODS}

The present cross-sectional study was conducted on 140 women and men with type 2 diabetes who had readmission in Bandar Abbas hospitals in 2017 selected by convenience sampling method. Data was collected using a questionnaire from patient. Data was analysed using statistical tests and SPSS software version 18.

\section{RESULTS}

The findings showed that individual factors (aging, occupational status, number of children, body mass index, exercise, smoking, history of smoking and narcotics) are among factors influencing the readmission of patients with type 2 diabetes.

\section{CONCLUSION}

Individual factors, some of which are non-adjustable, increase the risk of readmission in patients with type 2 diabetes.

\section{KEY WORDS}

Individual Factors, Readmission, Type 2 Diabetes.

HOW TO CITE THIS ARTICLE: Dashtpour V, Hesaraki M, Abavisani M, et al. Investigating individual factors related to readmission of patients with type 2 diabetes. A cross-sectional study. J. Evolution Med. Dent. Sci. 2018;7(53):5604-5609, D0I: $10.14260 /$ jemds/2018/1240

\section{BACKGROUND}

Diabetes mellitus, especially type 2 diabetes, is one of the main threats to human health in the 21st century.(1-3) Type 2 diabetes is a very common disease, which with its micro vascular and macro vascular complications, is the major cause of increase mortality (Three to six times) in people with diabetes. ${ }^{(4-6)} \mathrm{A}$ large percentage of mortality in patients with this disease is allocated to macro vascular complications (heart attacks), as the mortality stems from cardiovascular diseases in people with diabetes is 2-3 times more than nondiabetic patients.(7-9) Another acute complication of type 2 diabetes is Hyperosmolar Hyperglycaemic Nonketotic Syndrome (HHNS), which is generated gradually and over a few days to several weeks. Insulin levels are normal in this condition.(10,11) Display of chronic complications of diabetes are related to high glucose levels of blood, that is why diabetics are exposed to complications such as blindness, heart diseases, neuropathy and nephropathy.(10,12) Personal characteristics of patients, such as age and low quality of life, are among the main causes of frequent hospitalization in

'Financial or Other Competing Interest': None.

Submission 28-11-2018, Peer Review 15-12-2018,

Acceptance 18-12-2018, Published 31-12-2018.

Corresponding Author:

Mehran Hesaraki,

Behdasht St., Zabol University of Medical Sciences,

Zabol, Iran.

E-mail: mehranhesaraki2@gmail.com

DOI: $10.14260 /$ jemds $/ 2018 / 1240$

\section{(c) $(1)$}

diabetic patients.(13,14) The study of Jiang et al. (2003), with title of Recurrent hospitalizations in diabetic patients in five US states, showed that despite the control of age, sex, and clinical features, the ratio of having frequent hospitalization in the Hispanic and non-Hispanic black races was higher with the white one, that this trend in people who were covered by medical care and those living in low income areas was similar compare to each other, and the incidence of complications of diabetes is different in various conditions which is related to age, race, and cost payer among the patients with numerous hospitalizations. The results of the study show that multiple admissions are a good indicator of the type of hospital service usage and costs in diabetic patients, and some of the hospitalization cases due to the disease and its complications can be prevented with quality outpatient care, which can be lead to self-centered patient management on his disease.(15) Estrada et al. (2009) conducted a study on the readmission following the diabetes in young patients in Illinois in Chicago state. The results showed that there was a significant correlation between recurrent admissions and non-type 1 diabetes and unemployment and staying at home. The annual income was replaced with employment status as a predictor of socioeconomic status in people with recurrent readmission.(16) Tsuchi Hashi et al. (2001) conducted a study on the investigation the clinical and socio-environmental factors affecting readmission in patients with congestive heart failure, with the aim of looking the demographic clinical and socio-environmental factors affecting readmission in Japan. In this study, factors such as age, sex, aetiology, disease 
class, discharge fraction, previous hospitalization due to congestive heart failure, hospitalization duration, accompanying diseases, drugs and socio-environmental factors including occupation, financial resources, living alone and patients' follow-up were evaluated. The results showed that in one year, $35 \%$ of patients (81 people) were hospitalized again.(17) Tzahibi et al. (2011) conducted a study on the reasons for patients' readmission in al-Zahra hospital in Isfahan. Findings of the research indicate that various factors can be involved in readmitting patients to the hospital, the most important of which can be mentioned in three areas of factors related to the patient (age, smoking), clinical factors and hospital factors.(18) Arab et al. (2010) conducted a study on investigation the causes of readmission in the hospitals of Tehran University of Medical Sciences. The results showed that the most renewed referrals were in over 60 -year old ages and the most important reasons for rereferencing in the second and third follow-up were treatment complications and relapse, which may indicate incomplete treatment in previous visits, disregard of treatment protocols, non-standard facilities and hospital facilities.(19) The rate of readmission of diabetics in childhood is 5 times that of normal people and in adolescence 2.5 times that of normal people.(20) Inadequate access to medical care and the difference in presenting the quality of care provided to diabetic patients leads to readmission of patients.(21) Readmission in patients with diabetes is about $30 \%$ in one year according to the patient's age and the stage of disease,(7) with each year of more affected to diabetes, $26 \%$ increase the risk of readmission.(16) In recent years, re-admission after hospital discharge can be used as a marker for assessing the quality and efficiency of hospital care levels for many clinical conditions. 17,18$)$ Investigating the causes of re-referrals to hospitals is one of the important issues of the actual use of hospital beds and the actual exploitation of hospital facilities. Short-term hurriedly discharging of the patient from the hospital will reduce the cost of treatment for the medical center and increase revenues for equity holders and physicians in the merit pay system, but accelerated discharge may increase re-referrals of patients due to treatment deficiency, infection or incorrect diagnosis and due to lack of attention to the necessity of monitoring the treatment of the patient instead of promoting the health, has led to decrease it and, in this way, the goal of promoting the health, decreasing the patient's pain the patient is sacrificed for the material interests of medical group.(22) Therefore, the present study seeks to answer this problem that which are the most important individual factors associated with the re-admission of type II diabetic patients in Bandar Abbas hospitals in 2017.

\section{MATERIALS AND METHODS}

The method of this research has been cross sectional study. The research population includes patients with type 2 diabetes who have readmission in Bandar Abbas hospitals in 2017. In this research, the convenience sampling method was used that is the researcher after obtaining permission from hospital authorities by referring to the hospitals of Bandar Abbas in three shifts in the morning, evening and night during the 6 months (From the beginning of July 2017 until the end of December 2017), and with gaining consent from the patients, selected all patients who have had readmission due to diabetes or complications of type 2 diabetes, and chose
140 patient with readmission using the sampling formula and taking into account the minimum of the readmission per year (10\%). $(9$ \&16) The conditions for entering the study were: being aware and able to answer the questions, being readmitted due to diabetes or its complications in one of hospitals in Bandar Abbas during the study period, at least one year from the diagnosis of their disease being obviously past, willing to participate in the study. The data collecting instrument was a questionnaire of 13 questions related to individual factors that was made by the researcher and content validity method was used to determine the validity of the questionnaire. That is after studying different books and articles, the data collection form was prepared and was evaluated and judged by 6 faculty members of the Faculty of Nursing and Midwifery of Islamic Azad University, Isfahan branch (Khorasgan). After collecting comments, the required changes were considered in that and the mentioned instrument was used. To determine the reliability of the questionnaire, a test-retest method was used. That is at first the questionnaire was completed by 10 patients with type 2 diabetes who were re-admitted and then again, one week later, the questionnaires were completed by these patients and the reliability of the instrument was confirmed with a correlation coefficient of over 0.86 . Collected data analysed using SPSS v 18. To describe the demographic characteristics, descriptive tests (percentage, frequency and mean) were used. A chi-square test was used for assessing the relationship between number of readmissions and demographic characteristics or risk factor. This study was approved by the Ethics Committee of Azad Khorasgan University where the study was conducted.

\section{RESULTS}

According to the results, the highest number (86) was for women in terms of gender. The highest percentage of readmission in the female group (48\%) is for those who have had the history of once-in-time readmission and in the male sex group (53\%), is for those who have had the history of more than two times of readmissions. (Table 1, Figure 1,2)

\begin{tabular}{|c|c|c|c|c|c|c|c|c|}
\hline \multirow{3}{*}{\multicolumn{2}{|c|}{ Variables }} & \multicolumn{6}{|c|}{ Readmission Rate } & $\begin{array}{c}\text { p- } \\
\text { Value }\end{array}$ \\
\hline & & \multicolumn{2}{|c|}{ Once } & \multicolumn{2}{|c|}{ Twice } & \multicolumn{2}{|c|}{$\begin{array}{l}\text { More than } \\
\text { Twice }\end{array}$} & \\
\hline & & $\mathbf{N}$ & $\%$ & $\mathbf{N}$ & $\%$ & $\mathbf{N}$ & $\%$ & \\
\hline \multirow[b]{2}{*}{ 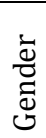 } & Female & 42 & 49 & 15 & 17 & 29 & 34 & \multirow[b]{2}{*}{0.3} \\
\hline & Male & 16 & 30 & 9 & 17 & 29 & 53 & \\
\hline \multirow{4}{*}{ 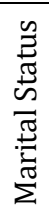 } & Married & 44 & 40 & 19 & 18 & 46 & 42 & \multirow{4}{*}{0.1} \\
\hline & Single & 4 & 67 & 1 & 17 & 1 & 16 & \\
\hline & Widow & 5 & 33 & 4 & 27 & 6 & 40 & \\
\hline & Other & 5 & 50 & 0 & 0 & 5 & 50 & \\
\hline \multirow{4}{*}{$\stackrel{\infty}{\infty}$} & $30-39$ & 17 & 68 & 3 & 12 & 5 & 20 & \multirow{4}{*}{0.01} \\
\hline & $40-49$ & 16 & 41 & 7 & 18 & 16 & 41 & \\
\hline & $50-59$ & 11 & 32 & 6 & 18 & 17 & 50 & \\
\hline & $60>$ & 14 & 34 & 8 & 19 & 20 & 47 & \\
\hline \multicolumn{9}{|c|}{$\begin{array}{l}\text { Table 1. Frequency Distribution of Patients according to } \\
\text { Individual Factors and Number of Readmissions }\end{array}$} \\
\hline
\end{tabular}



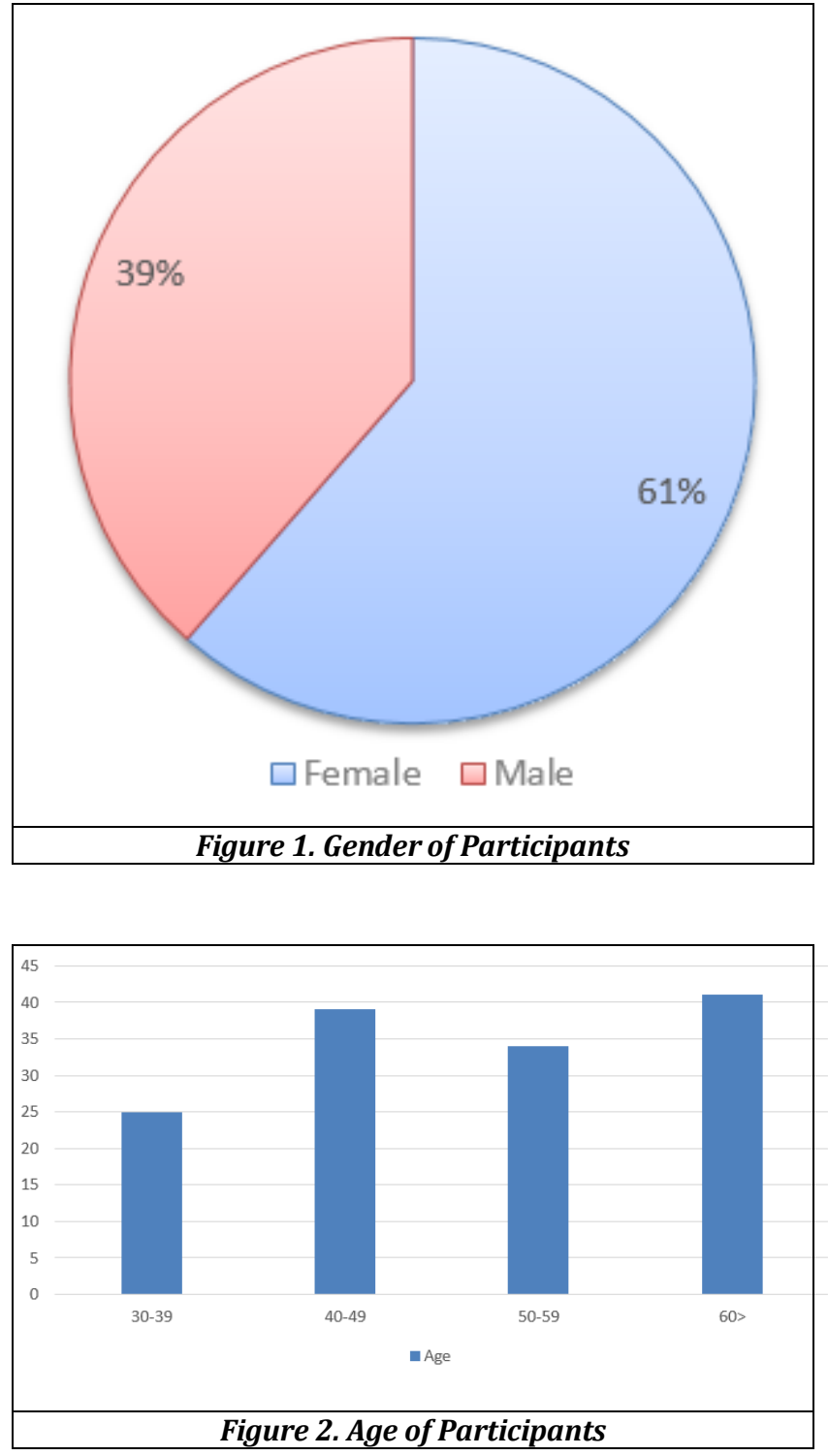

However, the statistical results of Chi-square test shows that there is no significant relationship between gender and readmission ( $\mathrm{p} \geq 0.05$ and $\mathrm{X}^{2}=7.23$ ). The table also shows that in terms of marital status the most frequent (109) was related to married people. In married people, the highest percentage of readmission (42\%) is for those with the history of more than two times of readmission. While in single individuals, the highest percentage $(67 \%)$ is for those with a history of once-in-time readmission. However, the results of Chi-square statistical test shows that there is no significant relationship between marriage and readmission ( $p \geq 0.05$ and $\mathrm{X}^{2}=5.24$ ). Also, in terms of age, most of the subjects (41) were over 60 years old. In the age group of 30-39 years, the highest frequency $(68 \%)$ is for individuals with a once-intime readmission history, while in the age group over 60 , the highest frequency $(47 \%)$ is for those with a history of more than two times of readmission. Chi-square statistic results shows that there is a significant relationship between age and readmission $\left(\mathrm{p} \leq 0.05\right.$ and $\left.\mathrm{X}^{2}=0.19\right)$.

\begin{tabular}{|c|c|c|c|c|c|c|c|c|c|c|}
\hline & & \multicolumn{6}{|c|}{$\begin{array}{c}\text { Number of } \\
\text { Readmissions }\end{array}$} & \multirow{2}{*}{\multicolumn{2}{|c|}{ Total }} & \multirow{3}{*}{$\begin{array}{c}\text { P- } \\
\text { Value }\end{array}$} \\
\hline \multirow[t]{2}{*}{ Variables } & & \multicolumn{2}{|c|}{ Once } & \multicolumn{2}{|c|}{ Twice } & \multicolumn{2}{|c|}{\begin{tabular}{|l|} 
More \\
than \\
Twice
\end{tabular}} & & & \\
\hline & & $\mathbf{N}$ & $\%$ & $\mathbf{N}$ & $\%$ & $\mathbf{N}$ & $\%$ & $\mathbf{N}$ & $\%$ & \\
\hline \multirow{6}{*}{ 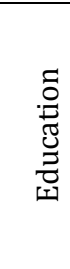 } & Illiterate & 14 & 45 & 3 & 10 & 14 & 45 & 31 & 100 & \multirow{6}{*}{0.12} \\
\hline & Elementary & 12 & 37 & 4 & 13 & 16 & 50 & 32 & 100 & \\
\hline & High School & 3 & 13 & 7 & 30 & 13 & 57 & 23 & 100 & \\
\hline & Diploma & 20 & 56 & 6 & 16 & 10 & 28 & 36 & 100 & \\
\hline & Bachelor & 7 & 50 & 3 & 21 & 4 & 29 & 14 & 100 & \\
\hline & $\begin{array}{l}\text { Higher } \\
\text { Bachelor }\end{array}$ & 2 & 50 & 1 & 25 & 1 & 25 & 4 & 100 & \\
\hline \multirow{7}{*}{ 응 } & Housewife & 34 & 51 & 12 & 18 & 21 & 31 & 67 & 100 & \multirow{7}{*}{0.03} \\
\hline & Worker & 3 & 33 & 0 & 0 & 6 & 67 & 9 & 100 & \\
\hline & Employee & 13 & 57 & 3 & 13 & 7 & 30 & 23 & 100 & \\
\hline & Retired & 2 & 33 & 3 & 50 & 1 & 17 & 6 & 100 & \\
\hline & Farmer & 2 & 25 & 1 & 13 & 5 & 62 & 8 & 100 & \\
\hline & \begin{tabular}{|c|} 
Free job \\
\end{tabular} & 3 & 16 & 4 & 21 & 12 & 63 & 19 & 100 & \\
\hline & Unemployed & 1 & 13 & 1 & 13 & 6 & 75 & 8 & 100 & \\
\hline \multirow{4}{*}{ 党 } & $1-2$ & 16 & 41 & 9 & 24 & 14 & 35 & 39 & 100 & \multirow{4}{*}{0.01} \\
\hline & $3-4$ & 21 & 42 & 9 & 18 & 20 & 40 & 50 & 100 & \\
\hline & $5-6$ & 14 & 58 & 5 & 21 & 5 & 21 & 24 & 100 & \\
\hline & $6>$ & 7 & \begin{tabular}{|l|}
26 \\
\end{tabular} & 1 & 4 & 19 & 70 & 27 & 100 & \\
\hline \multicolumn{11}{|c|}{$\begin{array}{l}\text { Table 2. Frequency Distribution of Patients according to } \\
\text { Individual Factors (Education, Occupation and Number of } \\
\text { Children), and the Number of Readmissions }\end{array}$} \\
\hline
\end{tabular}

According to Table 2, in terms of education, the highest number of frequencies (36 people) was for those with diploma. The highest frequency percentage of readmission in illiterate people $(45 \%)$ is seen both in those with one readmission history and in those with history of more than two times of readmissions. The highest percentage of frequency in the groups of diploma (56\%), bachelor (50\%) and higher than bachelor $(50 \%)$ is seen in individuals with a once-in-time re-admission history. The highest frequency in individuals with primary education (50\%) and diploma $(57 \%)$ has been seen in people with more than twice of readmissions. Chi-square test shows that there is no significant relationship between education level and readmission $\left(\mathrm{p} \geq 0.05\right.$ and $\left.\mathrm{X}^{2}=20.07\right)$. The table also shows that in terms of employment status the highest number (67 people) was in house keepers. The highest frequency is observed in housekeepers (50\%) and employees (56\%) in the group of people with the history of one-time readmission and the highest frequency of the unemployed (75\%), worker (66\%), farmer (62\%) and freelancers (63\%) in people with a history of more than twice of readmission history. The results of chi-square statistical test show that there is a significant relationship between occupations and re-admission ( $\mathrm{p} \leq 0.05$ and $\mathrm{X}^{2}=40.83$ ). In terms of the number of children, table 2 also shows that the highest frequency (50 people) was for those with 3 to 4 children. The highest frequency percentage in those with 1 to 2 children (41\%) is seen in the group with a history of one time of readmission and the highest frequency in people with more than 6 children $(70 \%)$ is seen in those with the history of more than twice of readmission. Chisquare statistical results show that there is a significant relationship between the number of children and the rate of readmission $\left(\mathrm{p} \leq 0.01\right.$ and $\left.\mathrm{X}^{2}=75.74\right)$ 


\begin{tabular}{|c|c|c|c|c|c|c|c|c|}
\hline \multirow{3}{*}{\multicolumn{2}{|c|}{ Variables }} & \multicolumn{6}{|c|}{ Number of Readmissions } & \multirow{3}{*}{$P$ value } \\
\hline & & \multicolumn{2}{|c|}{ Once } & \multicolumn{2}{|c|}{ Twice } & \multicolumn{2}{|c|}{$\begin{array}{c}\text { More } \\
\text { than } \\
\text { Twice }\end{array}$} & \\
\hline & & $\mathbf{N}$ & $\%$ & $\mathbf{N}$ & $\%$ & $\mathbf{N}$ & $\%$ & \\
\hline \multirow{2}{*}{ Exercise } & No & 44 & 44 & 16 & 16 & 39 & 40 & \multirow{2}{*}{0.01} \\
\hline & Yes & 14 & 34 & 8 & 19 & 19 & 46 & \\
\hline \multirow{2}{*}{ BMI } & Normal & 24 & 41 & 10 & 17 & 25 & 42 & \multirow{2}{*}{0.04} \\
\hline & Obesity & 28 & 49 & 9 & 16 & 20 & 35 & \\
\hline \multicolumn{9}{|c|}{$\begin{array}{l}\text { Table 3. Frequency Distribution of Patients according to } \\
\text { Individual Factors (BMI and Exercise) and Number of } \\
\text { Readmissions }\end{array}$} \\
\hline
\end{tabular}

According to Table 3, in terms of doing exercise, the highest frequency (99 people) was for those who do not exercise. The highest percentages in the group who do not exercise (44\%) were for those who had one-time hospitalization history, but in those who usually exercise, the highest frequency (46\%) was for those who had the history of more than twice readmission. The results of chi-square statistical test shows that there was a significant relationship between exercise and re-admission $\left(p \leq 0.01\right.$ and $X^{2}=1$. 79). Also, in terms of body mass index, the highest frequency (59 people) were those who had a BMI in the normal range. The highest frequency in overweight individuals (49\%) was for those with once readmission history and the highest frequency in people with normal weight $(41 \%)$ and obese (54\%) were in the group with more than two times of readmission. The results of chi-square statistical test shows that there is a significant relationship between body mass index and re-admission of patients $\left(p \leq 0.05\right.$ and $\left.X^{2}=0.30\right)$.

According to table 4, in terms of smoking, the highest frequency (117 people) was for those who do not currently smoke. The highest percentage of people who are not currently smokers (43\%), in the group with the history of one-time readmission and the highest percentage of currently smokers (52\%) is in the group with a history of more than twice of readmission. The results of chi-square statistical test shows that there is a significant relationship between current smoking and re-admission $\left(\mathrm{p} \leq 0.05\right.$ and $\left.\mathrm{X}^{2}=8.33\right)$. The table also shows that in terms of smoking history the highest frequency ( 99 people) were those who did not have a history of smoking. The highest percentages in the non-smokers group (47\%) were those who had one-time readmission, and the highest percentage of frequency in people with a history of smoking (58\%) belonged to those who had a history of more than twice readmission. The results of chi-square statistical test shows that there is a significant relationship between smoking history and re-admission ( $\mathrm{p} \leq 0.01$ and $\mathrm{X}^{2}=28.87$ ). Also, regarding the history of drug abuse, the highest frequency (114) was for people who did not have a history of drug abuse. The highest percentages in the group with no history of drug abuse (46\%) were those who had the history of one-time readmission, and the highest percentage of people with drug abuse history (62\%) belonged to those who have had the history of more than twice readmission. The statistical results of chi-square show that there is a significant relationship between the history of drug abuse and re-admission $\left(\mathrm{p} \leq 0.01\right.$ and $\left.\mathrm{X}^{2}=10.39\right)$.

\begin{tabular}{|c|c|c|c|c|c|c|c|c|}
\hline \multirow{3}{*}{\multicolumn{2}{|c|}{ Variable }} & \multicolumn{6}{|c|}{ Number of readmissions } & \multirow{3}{*}{ P Value } \\
\hline & & \multicolumn{2}{|c|}{ Once } & \multicolumn{2}{|c|}{ Twice } & \multicolumn{2}{|c|}{$\begin{array}{c}\text { More than } \\
\text { twice }\end{array}$} & \\
\hline & & $\mathbf{N}$ & $\%$ & $\mathbf{N}$ & $\%$ & $\mathbf{N}$ & $\%$ & \\
\hline \multirow{2}{*}{$\begin{array}{l}\text { Current } \\
\text { smoker }\end{array}$} & No & 50 & 43 & 21 & 18 & 46 & 39 & \multirow{2}{*}{0.01} \\
\hline & Yes & 8 & 35 & 3 & 14 & 12 & 52 & \\
\hline \multirow{2}{*}{$\begin{array}{c}\text { History of } \\
\text { smoking }\end{array}$} & No & 47 & 47 & 18 & 19 & 34 & 35 & \multirow{2}{*}{0.01} \\
\hline & Yes & 11 & 27 & 6 & 15 & 24 & 58 & \\
\hline \multirow{2}{*}{$\begin{array}{l}\text { History of } \\
\text { drug use }\end{array}$} & No & 53 & 46 & 19 & 17 & 42 & 37 & \multirow{2}{*}{0.01} \\
\hline & Yes & 5 & 19 & 5 & 19 & 16 & 62 & \\
\hline
\end{tabular}

\section{DISCUSSION}

Table 1 shows that most of the units studied are women, and the majority of sample women in the study have been in a group with the history of one-time readmission and the majority of sample men in the study have been in the group with the history of more than twice readmission. However, chi-square statistical test did not show significant correlation between gender and re-admission. Table 1 also shows that the majority of sampled diabetic patients with a history of readmission in the present study were married. Chi-square statistical test results show that there is no significant relationship between marital status and re-admission. Table 1 also shows that the majority of diabetic patients with readmission have been in the age group of 60 years and older. Chi-square statistical results shows that a significant relationship between age and readmission rate is reached. In justifying this finding, it can be said that the longer the age of diabetics is, there is more possibility for readmission. So that the prevalence of diabetes from $1.4 \%$ in the age group of 25 44 years old reaches more than $10 \%$ in the age of over 65 years and in other words an increase of 7 times in the prevalence of the disease is seen compared with the ages under 45 years. Therefore, international communities suggest that in people over the age of 45 , at least every three years, fasting blood sugar should be measured. Tazhibi et al. (2011) in a study on the causes of readmission of patients in al-Zahra hospital of Isfahan showed that in age groups, the highest rate $(29.8 \%)$ was allocated to the age group over 60 years old.(18) The study Silverstine (2008) with the title of the risk factor for 30-day readmission in patients over 65 years old also showed that 75-year-olds and more is involved in readmission.(23) In the study of Lyratzopoulos (2005), with the title of the factors influencing readmission in Manchester, England, it was revealed that the male gender and age above 75 years results in a high rate of readmission within 3,6 , and 12 months after discharge.(24)

The results also show that the majority of diabetic patients $(26 \%)$ have diploma education and there is no significant relationship between education level and readmission. On the other hand, the result showed that the majority of diabetic patients were housewives in the whole sample. And the results of chi-square statistical test also show that there is a significant relationship between occupation and readmission. It seems that since most diabetic patients are women, it is natural that they are housewives. In the study of Tsuchiki Hashi et al. (2001), lack of job was reported as effective factors in the readmission of diabetics.(17) 
Estrada et al. (2009) conducted a study on readmission following diabetes in young patients in Illinois, Chicago. In single-variable statistical analysis, frequent readmissions (More than once in the first year of diagnosis) had a significant relationship with the lack of insurance coverage, and unemployment and being homebound.(16) The results also showed that the majority of diabetic patients in terms of the number of children in total is related to families with 4- 3 children. Results showed that there is a significant relationship between the number of children and the rate of readmission. That means, in fact, the more the number of children in the family, the greater the probability of readmission of patients with diabetes. It seems that with increasing the number of family members, economic and educational problems will increase and stress increases in the family. The results show that the majority of diabetic patients do not exercise and the results of chi-square statistical test shows that there is a significant relationship between the level of exercise and re-admission. So that readmission in people who exercise is more. This is perhaps due to this reason that the patients do not do the principled exercise and therefore suffer more from the effects of exercise, so further research is needed. In general, the gradual and slow increase in exercise time is recommended. Table 3 also shows that the majority of diabetics have normal BMI. The results of chisquare statistical test show that there is a significant relationship between BMI and re-admission of patients. Body mass index affects weight gain, and weight gain of diabetic patients and lack of proper diet has a significant role in readmission. Molina Corona (2010) also showed that $74 \%$ of patients had a high body mass index.(25) These results are corresponded to the present study. Table 4 shows that the majority of diabetic patients currently do not smoke and the results of chi-square statistical test shows that there is a significant relationship between the current smoking levels and readmission. Since cigarette is a discrete and moderator factor for type 2 diabetes, it is natural that continuing its usage will accelerate the effects of the disease and readmission. Table 4 also showed that the majority of diabetic patients did not have a history of smoking, and the results of chi-square statistical test showed that there is a significant relationship between the level of current smoking and re-admission. Results also shows that the majority of diabetic patients did not have a history of drug abuse, and the results of the chi-square statistical test confirm that there is a significant relationship between the history of drug use and the rate of readmission. ${ }^{26,27)}$ Narcotic and cigarettes in a long time along with body mass index of fat body causes the blood pressure to rise, the amount of sugars and fats in the body to be added and causes diabetes.

\section{CONCLUSION}

Individual factors such as aging, occupational status, number of children, body mass index, exercise, smoking, and smoking history, and narcotics, some of which are non-adjustable, increase the risk of readmission in patients with type 2 diabetes.

\section{REFERENCES}

[1] Powers MA, Bardsley J, Cypress M, et al. Diabetes selfmanagement education and support in type 2 diabetes. The Diabetes Educator 2017;43(1):40-53.
[2] Goyal R, Jialal I. Diabetes mellitus, Type 2. StatPearls [Internet], Treasure Island (FL), StatPearls Publishing Oct 27, 2018.

[3] Neal B, Perkovic V, Mahaffey KW, et al. Canagliflozin and cardiovascular and renal events in type 2 diabetes. New England Journal of Medicine 2017;377(7):64457.

[4] Imura H. Diabetes: current perspectives. N Engl J Med 2000;342:1533.

[5] Zheng Y, Ley SH, Hu FB. Global aetiology and epidemiology of type 2 diabetes mellitus and its complications. Nature Reviews Endocrinology 2018;14(2):88-98.

[6] Cersosimo E, Triplitt C, Solis-Herrera C, et al. Pathogenesis of type 2 diabetes mellitus. Updated: Feb 27, 2018.

[7] Moulik PK, Mtonga R, Gill GV. Amputation and mortality in new-onset diabetic foot ulcers stratified by etiology. Diabetes Care 2003;26(2):491-4.

[8] Ziukaite L, Slot DE, Van der Weijden FA. Prevalence of diabetes mellitus in people clinically diagnosed with periodontitis: a systematic review and meta-analysis of epidemiologic studies. Journal of Clinical Periodontology 2018;45(6):650-62.

[9] Markle-Reid M, Ploeg J, Fraser KD, et al. community program improves quality of life and self-management in older adults with diabetes mellitus and comorbidity. Journal of the American Geriatrics Society 2018;66(2):263-73.

[10] American Diabetes Association. Diagnosis and classification of diabetes mellitus. Diabetes Care 2014;37(Suppl 1):S81-S90.

[11] Han SJ, Boyko EJ. The evidence for an obesity paradox in type 2 diabetes mellitus. Diabetes \& Metabolism Journal 2018;42(3):179-87.

[12] Svensson AK, Svensson T, Kitlinski M, et al. Incident diabetes mellitus may explain the association between sleep duration and incident coronary heart disease. Diabetologia 2018;61(2):331-41.

[13] Mejhert M, Kahan T, Persson H, et al. Predicting readmissions and cardiovascular events in heart failure patients. International Journal of Cardiology 2006;109(1):108-13.

[14] Dieplinger B, Mueller T. Afamin an emerging marker for type 2 diabetes mellitus. Journal of Laboratory and Precision Medicine 2018;3(1):5.

[15] Jiang HJ, Stryer D, Friedman B, et al. Multiple hospitalizations for patients with diabetes. Diabetes Care 2003;26(5):1421-6.

[16] Estrada CL, Danielson KK, Drum ML, et al. Hospitalization subsequent to diagnosis in young patients with diabetes in Chicago, Illinois. Pediatrics 2009;124(3):926-34.

[17] Tsuchihashi M, Tsutsui H, Kodama K, et al. Medical and socioenvironmental predictors of hospital readmission in patients with congestive heart failure. American Heart Journal 2001;142(4):20A-6A.

[18] Tazhibi M, Ghaderi NL, Tirani M. Causes of readmission of patients to Al Zahra hospital, Iran. Health System Research 2011;7(1):101-7. 
[19] Tavakoli N, Taherizade AR, Tahmasbi A, et al. A survey on factors contributing to hospital patient readmission. International Journal of Hospital Research 2013;2(2):85-90.

[20] Rubin DJ. Hospital readmission of patients with diabetes. Current Diabetes Reports 2015;15(4):17.

[21] CDC \& Prevention. National diabetes fact sheet: national estimates and general information on diabetes and prediabetes in the United States, 2011. Atlanta, GA: US Department of Health and Human Services, Centers for Disease Control and Prevention. 2011;201(1)

[22] Barrière DA, Noll C, Roussy G, et al. Combination of high-fat/high-fructose diet and low-dose streptozotocin to model long-term type- 2 diabetes complications. Scientific Reports 2018;8(1):424.

[23] Silverstein MD, Qin H, Mercer SQ, et al. Risk factors for 30-day hospital readmission in patients $\geq 65$ years of age. Proceedings (Baylor University Medical Center) 2008;21(4):363-72.
[24] Lyratzopoulos G, Havely D, Gemmell I, et al. Factors influencing emergency medical readmission risk in a UK district general hospital: a prospective study. BMC Emergency Medicine 2005;5(1):1.

[25] Molina-Corona A, Zonana-Nacach A. Readmisión hospitalaria de pacientes diabéticos: seguimiento de 12 meses. Revista Médica del Instituto Mexicano del Seguro Social 2010;48(5):469-74.

[26] Medina-Remón A, Kirwan R, Lamuela-Raventós RM, et al. Dietary patterns and the risk of obesity, type 2 diabetes mellitus, cardiovascular diseases, asthma, and neurodegenerative diseases. Critical Reviews in Food Science and Nutrition 2018;58(2):262-96.

[27] Targher G, Lonardo A, Byrne CD. Non-alcoholic fatty liver disease and chronic vascular complications of diabetes mellitus. Nature Reviews Endocrinology 2018;14(2):99-114. 